\title{
Synthesis of Hierarchical CoO Nano/Microstructures as Anode Materials for Lithium-Ion Batteries
}

\author{
Dan Qin, Peng Yan, Guangzhong Li, Yunchuang Wang, Yukuan An, and Juan Xing \\ Binzhou Medical University, Guanhai Road 346, Yantai 264003, China \\ Correspondence should be addressed to Peng Yan; yp_ok@163.com
}

Received 25 June 2014; Accepted 16 July 2014; Published 6 August 2014

Academic Editor: Xijin Xu

Copyright (C) 2014 Dan Qin et al. This is an open access article distributed under the Creative Commons Attribution License, which permits unrestricted use, distribution, and reproduction in any medium, provided the original work is properly cited.

Hierarchical $\mathrm{CoO}$ nano/microstructures are synthesized via a hydrothermal method and a subsequent annealed process. When evaluated for use in lithium-ion batteries, hierarchical $\mathrm{CoO}$ nano/microstructures show a high initial discharge capacity of $1370 \mathrm{mAh} / \mathrm{g}$ and a high reversible capacity of $1148 \mathrm{mAh} / \mathrm{g}$ over 20 cycles at a current density of $100 \mathrm{~mA} / \mathrm{g}$. Superior rate performance with coulombic efficiency of about $100 \%$ upon galvanostatic cycling is also revealed. The excellent electrochemical properties of hierarchical $\mathrm{CoO}$ nano/microstructures make it a promising alternative anode material for high power lithium-ion batteries applications.

\section{Introduction}

The ever-increasing demands for the high power rechargeable lithium-ion batteries (LIBs) have been propelling the researches on the high performance electrode materials $[1,2]$ The commercialized graphite-based anode materials exhibit excellent charge and discharge cycling performance, but their low specific capacities are far from the requirement of the high energy LIBs [3]. Recently, transition metal oxides (MO, where $\mathrm{M}$ refers to $\mathrm{Co}, \mathrm{Fe}, \mathrm{Ti}$, or $\mathrm{Ni}$ ) have aroused intense interests in the field of LIBs since their high electrochemical capacities were first reported by Poizot et al. [4]. Different from the classical intercalation reaction, the conversion reaction mechanism is adopted in transition metal oxides for the lithium-ion storage [5]. Theoretical and experimental investigations further demonstrate the occurrence of the multiple redox reaction between the transition metal oxides and lithium, which will lead to the high capacities in the transition metal oxides based LIBs [6-10].

Cobalt monoxide $(\mathrm{CoO})$ with a relatively high theoretical capacity of $715 \mathrm{mAh} / \mathrm{g}$ is one of the potential candidate anode materials for rechargeable LIBs [11]. However, similar to other transition metal oxides anode materials, the poor cycle stability and rate capability of $\mathrm{CoO}$ anode materials hamper their large scale practical applications in LIBs [12-14]. Previous studies show that the poor electrochemical performance of
$\mathrm{CoO}$ anode materials is mainly due to the low conductivity and drastic volume change during lithiation/delithiation cycles $[15,16]$. In recent years, considerable efforts have been devoted to overcome this drawback and an intuitively straightforward route is to decrease the size of the $\mathrm{CoO}$ anode materials to nanoscale [17-19]. Nanosized electrode materials with high specific surface may increase the contact area between the electrolyte and electrode materials and shorten the path length for $\mathrm{Li}$ ion transport during electrochemical reaction, which would do favor to the improvement of the discharge capacities [20-22].

In this paper, we report the synthesis of hierarchical $\mathrm{CoO}$ nano/microstructures via a hydrothermal method followed by a subsequent thermal annealing process. Hierarchical $\mathrm{CoO}$ nano/microstructures with the size of 5-7 $\mu \mathrm{m}$ are consisting of many nanoparticles chains. The as-synthesized hierarchical $\mathrm{CoO}$ nano/microstructures exhibit a high initial capacity of about $1370 \mathrm{mAh} / \mathrm{g}$ and superior cycle stability. Good rate capability is also obtained in $\mathrm{CoO}$ nano/microstructures as anode materials for LIBs.

\section{Experimental}

The detailed synthesis process of hierarchical $\mathrm{CoO}$ nano/microstructures is described as follows. To begin, $1.50 \mathrm{~g}$ 
$(25 \mathrm{mmol})$ of urea and $0.05 \mathrm{~g}$ of cetyltrimethylammonium bromide (CTAB) are dissolved in $30 \mathrm{~mL}$ of deionized water under magnetic stirring. After the solution becomes transparent, $10 \mathrm{~mL} 0.5 \mathrm{M}$ of $\mathrm{CoSO}_{4} \cdot 7 \mathrm{H}_{2} \mathrm{O}$ is added and stirred for another 10 minutes. Finally, the whole mixture is transferred into a Teflon-lined autoclave and maintained at $120^{\circ} \mathrm{C}$ for $12 \mathrm{~h}$. When the autoclave is cooled to room temperature naturally, the rosy products are collected by filtration, rinsed several times with deionized water and absolute ethyl alcohol, and dried at $60^{\circ} \mathrm{C}$. Finally, black CoO materials are obtained by thermal decomposition of the rosy precursor at $500^{\circ} \mathrm{C}$ for $2 \mathrm{~h}$ in a vacuum of $10^{-5}$ torr.

The samples are characterized by X-ray powder diffraction (XRD, Philips X'pert $\mathrm{PRO}$ diffractometer, $\mathrm{Cu} \mathrm{K} \alpha$ radiation), field emission scanning electron microscopy (FESEM, Hitachi S-4800, Japan), and high-resolution transmission electron microscopy (HRTEM, JEOL, 2010, $200 \mathrm{kV}$ ). To investigate the electrochemical properties of the as-prepared $\mathrm{CoO}$ hierarchical nano/microstructures, two-electrode cointype cells are assembled with lithium metal as counter and reference electrodes. The working electrode was fabricated by spreading the mixture of $\mathrm{CoO}$, acetylene black (ATB), and polyvinylidene fluoride (PVDF) in a weight ratio of $7: 2: 1$ onto the copper foil. The electrode was then dried at $120^{\circ} \mathrm{C}$ for $2 \mathrm{~h}$ and cut into a disk. The electrolyte solution was $1 \mathrm{M}$ $\mathrm{LiPF}_{6}$ dissolved in a mixture of ethylene carbonate (EC) and diethyl carbonate (DEC) with the volume radio of EC/DEC = $1: 1$. Cyclic voltammograms (CVs) test is conducted at room temperature, using the electrochemical workstation $(\mathrm{CHI}$ $660 \mathrm{C}$ ) at a scan rate of $0.2 \mathrm{mV} / \mathrm{s}$ in a range of $0.01-3.0 \mathrm{~V}$ versus $\mathrm{Li} / \mathrm{Li}^{+}$. The rate capacity and the cycle performance are measured by a galvanostatic discharge-charge method at current densities of $100 \mathrm{~mA} / \mathrm{g}, 200 \mathrm{~mA} / \mathrm{g}, 300 \mathrm{~mA} / \mathrm{g}$, and $500 \mathrm{~mA} / \mathrm{g}$, respectively, in the range of $0.01-3.0 \mathrm{~V}$ with a multichannel battery test system (Land CT 2001A).

\section{Results and Discussion}

The crystalline phase of the as-prepared products was analyzed by XRD. Figure 1(a) shows the diffraction patterns for the products. All the characteristic diffraction peaks can be assigned to cubic CoO (JCPDS 78-0341, $a=4.2602 \AA$ ). In addition, no additional diffraction peaks were detected, indicating the high purity of the $\mathrm{CoO}$ products. FESEM image (Figure 1(b)) illustrates the typical morphologies of the obtained $\mathrm{CoO}$ products. These $\mathrm{CoO}$ products are of hierarchical structures with diameters in the range of 5$7 \mu \mathrm{m}$. Figure $1(\mathrm{c})$ represents the TEM image of a single $\mathrm{CoO}$ hierarchical structure, which is assembled from many nanosized branches radiating from a center. The HRTEM image (Figure 1(d)) further demonstrates that these radial nanosized branches are composed of numerous nanoparticles with the size of several nanometers. The measured lattice spacing of $0.216 \mathrm{~nm}$ corresponds to the (200) planes of cubic CoO.

Cyclic voltammogram (CV) measurements were carried out to investigate the electrochemical properties of the hierarchical $\mathrm{CoO}$ nano/microstructures as anode materials for the LIBs. Figure 2 shows the first three CV curves at a scan rate of $0.2 \mathrm{mV} / \mathrm{s}$ in the range of $0.01-3.0 \mathrm{~V}$. In the first cycle, a wide and irreversible reduction peak at about $0.20 \mathrm{~V}$ is observed, corresponding to the electrochemical lithiation reaction of the $\mathrm{CoO}$ and the formation of the solid electrolyte interface (SEI) layer. Previous studies reveal that the SEI layer might be formed on the surface of the transition metal oxides and results in the irreversible peak in the first $\mathrm{CV}$ curve $[23,24]$. In the anodic scan process, a broad anodic peak is recorded at about $2.3 \mathrm{~V}$, which is ascribed to the complex oxidation of metallic cobalt to cobalt oxide. The total chemical reaction can be expressed as $\mathrm{CoO}+2 \mathrm{Li} \leftrightarrow \mathrm{Li}_{2} \mathrm{O}$ + Co [11]. The CV curve of the second cycle nearly overlaps with the curve for the third cycle, indicating the good cyclic stability of the CoO.

To investigate the lithium storage capacity, the galvanostatic discharge-charge performances were measured in the voltage window of $0.01-3.0 \mathrm{~V}$ at a current density of $100 \mathrm{~mA} / \mathrm{g}$. Figure 3 displays the $1 \mathrm{st}, 2 \mathrm{nd}$, and $20 \mathrm{th}$ galvanostatic discharge-charge curves for the hierarchical $\mathrm{CoO}$ nano/microstructures. A long potential plateau at about $1.0 \mathrm{~V}$, followed by a sloping curve down to the cutoff voltage of $0.01 \mathrm{~V}$, is clearly observed from the first discharge curve. The long potential plateau could be ascribed to the conversion reaction between $\mathrm{CoO}$ and $\mathrm{Li}$, while the sloping curve corresponds to the formation of the SEI layer [25]. The initial specific discharge capacity goes up to as much as $1370 \mathrm{mAh} / \mathrm{g}$, which is much higher than its theoretical value of $715 \mathrm{mAh} / \mathrm{g}$. The extra capacity could be ascribed to the formation of a polymer-gel-like film during the reduction process of $\mathrm{CoO}$ to $\mathrm{Co}$ and the formation of a $\mathrm{Co} / \mathrm{Li}_{2} \mathrm{O}$ interface in the course of the heterogeneous solid-state reaction process [26]. For the first charge, a voltage plateau at around $2.3 \mathrm{~V}$ is recorded, corresponding to the process of oxidation of metallic Co to $\mathrm{CoO}$ and the decomposition of the $\mathrm{Li}_{2} \mathrm{O}$, which is in accord with the $\mathrm{CV}$ measurement. The initial coulombic efficiency reaches $71.5 \%$ with the discharge and charge capacities of 1370 and $981 \mathrm{mAh} / \mathrm{g}$, respectively. Compared to the initial discharge/charge curve, the discharge curves undergo a notable change in subsequent cycles, with shorter potential plateaus and longer sloping ranges. After the 20th cycle, the discharge and the charge capacities become 1148 and $1119 \mathrm{mAh} / \mathrm{g}$, respectively, demonstrating the good capacity retention and cycle stability of the as-prepared hierarchical $\mathrm{CoO}$ nano/microstructures materials.

Figure 4 shows the discharge capacities of the as-prepared hierarchical $\mathrm{CoO}$ nano/microstructures as a function of the cycle number at different current densities. The $\mathrm{CoO}$ materials display a superior cyclic stability as well as high capacity. The initial discharge capacity is $1370 \mathrm{mAh} / \mathrm{g}$ at a current density of $100 \mathrm{~mA} / \mathrm{g}$. The discharge capacity of the 20th cycle is as high as $1144 \mathrm{mAh} / \mathrm{g}$, which is $83.5 \%$ of the first discharge capacities. The rate performance of the hierarchical $\mathrm{CoO}$ nano/microstructures is also revealed, and the discharge capacities at $100 \mathrm{~mA} / \mathrm{g}, 200 \mathrm{~mA} / \mathrm{g}, 300 \mathrm{~mA} / \mathrm{g}$, and $500 \mathrm{~mA} / \mathrm{g}$ are $1370 \mathrm{mAh} / \mathrm{g}, 1040 \mathrm{mAh} / \mathrm{g}, 822 \mathrm{mAh} / \mathrm{g}$, and $593 \mathrm{mAh} / \mathrm{g}$, respectively. Even under the high current density of $500 \mathrm{~mA} / \mathrm{g}$, the capacity of $\mathrm{CoO}$ is still higher than the theoretical capacity of commercial graphite anodes' materials 


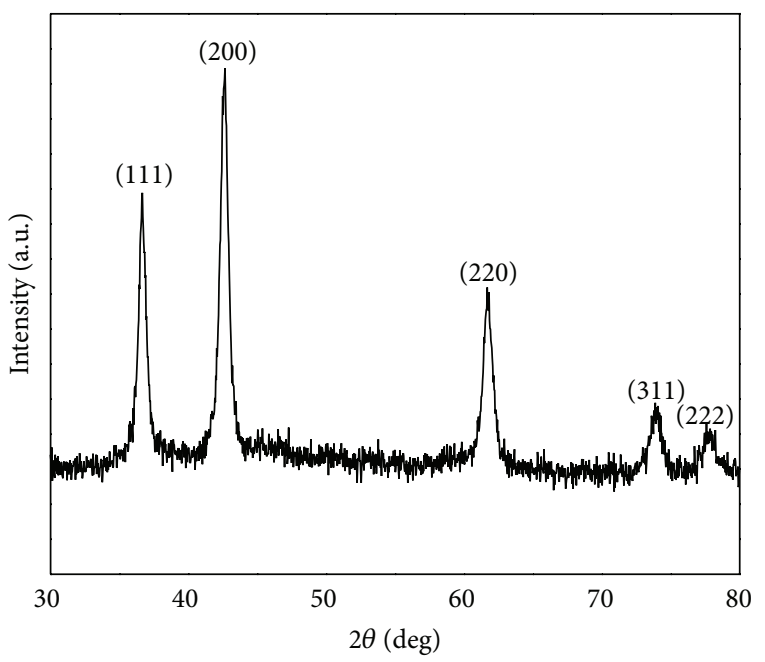

(a)

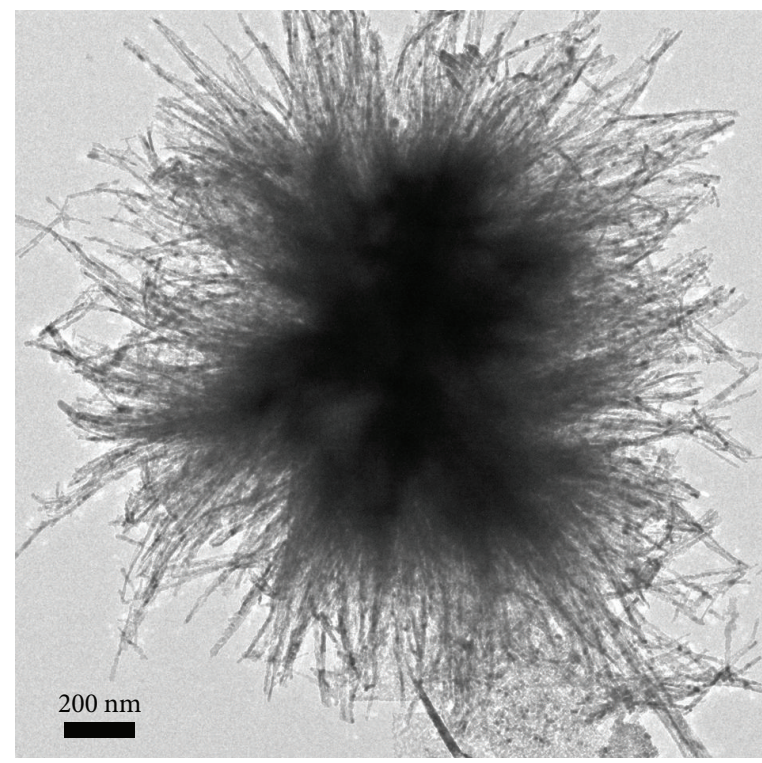

(c)

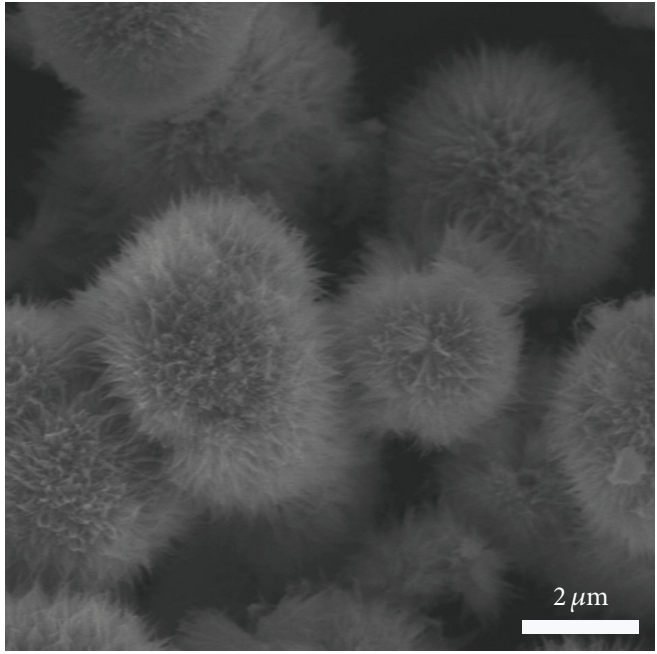

(b)

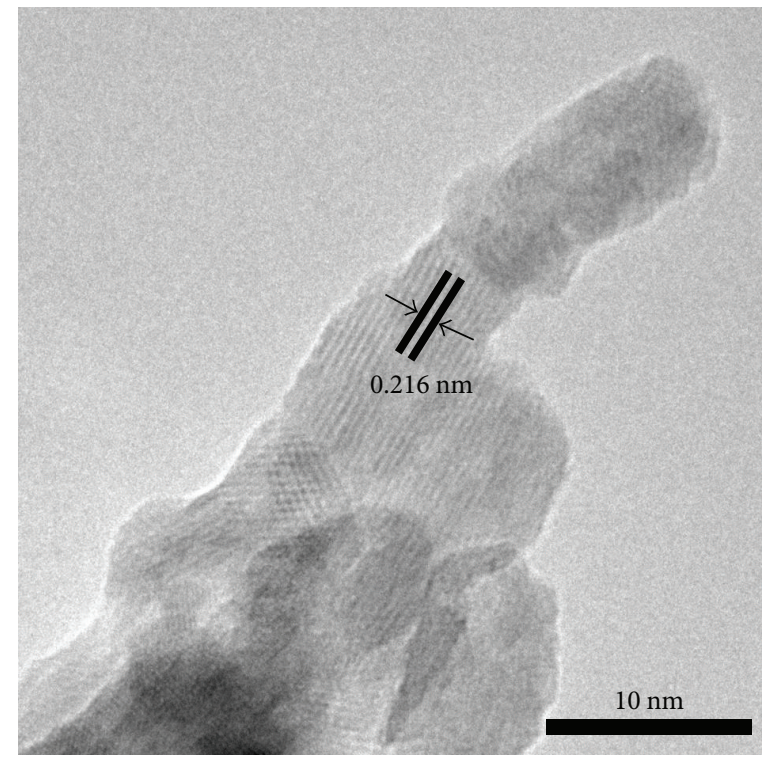

(d)

FIGURE 1: (a) XRD pattern of the as-prepared $\mathrm{CoO}$ products. ((b)-(d)) Characterization of hierarchical CoO nano/microstructures: (b) FESEM image, (c) TEM image, and (d) HRTEM image.

of $372 \mathrm{mAh} / \mathrm{g}$. Moreover, when the current density reduces to $100 \mathrm{~mA} / \mathrm{g}$ again, the capacity reaches back to $1054 \mathrm{mAh} / \mathrm{g}$ accordingly. The coulombic efficiency of the $\mathrm{CoO}$ is close to $100 \%$ during the cycles.

The superior electrochemical performance of the asprepared hierarchical $\mathrm{CoO}$ nano/microstructures might originate from their unique nano/microstructures. The hierarchical $\mathrm{CoO}$ nano/microstructures with the size of several micrometers are composed of many $\mathrm{CoO}$ nanoparticles chains. The high specific surface of the $\mathrm{CoO}$ nanoparticles and the large porosity of the hierarchical nano/microstructures increase the contact area between the electrolyte and $\mathrm{CoO}$ electroactive materials and shorten the path length for $\mathrm{Li}^{+}$transport, improving the discharge capacity and the cycle stability of the $\mathrm{CoO}$ as anode materials for LIBs. Furthermore, the good rate performance of the $\mathrm{CoO}$ can be attributed to the electrochemical milling effect [27, 28 ], which can be observed in various metal oxides systems, including $\mathrm{Fe}_{3} \mathrm{O}_{4}$ and $\mathrm{Cu}_{2} \mathrm{O}-\mathrm{Li}_{2} \mathrm{O}$ composite electrodes.

\section{Conclusion}

Hierarchical CoO nano/microstructures have been successfully synthesized by using a hydrothermal method and 


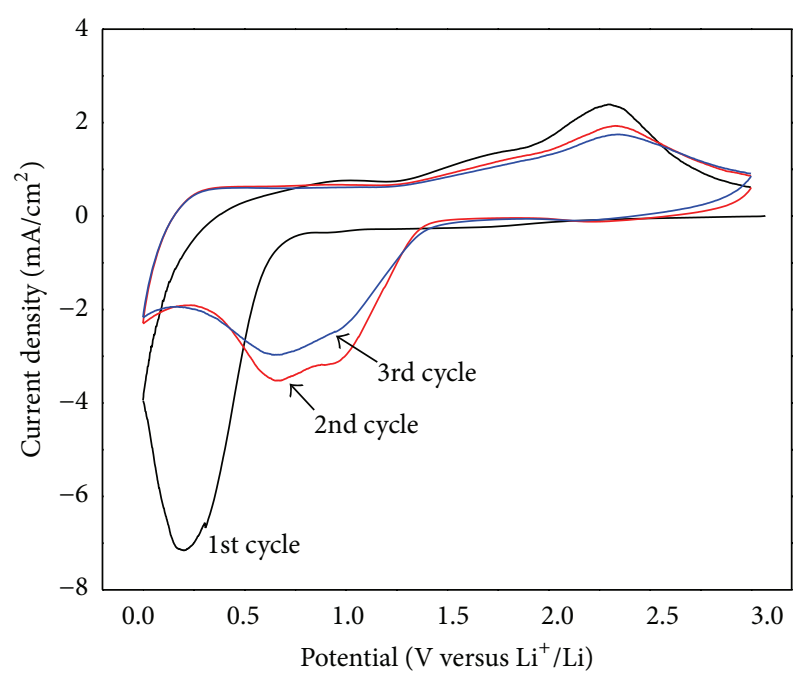

FIgURE 2: First three cyclic CV curves of the hierarchical CoO nano/microstructures at a scan rate of $0.2 \mathrm{mV} / \mathrm{s}$.

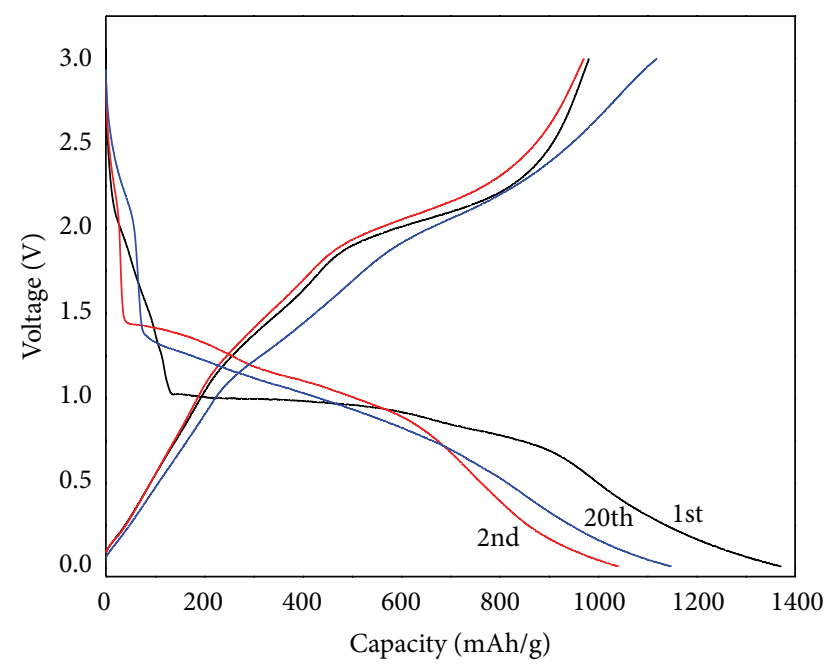

FIgURE 3: The galvanostatic discharge-charge profiles of the $\mathrm{CoO}$ electrode at a current density of $100 \mathrm{~mA} / \mathrm{g}$ between $0.01 \mathrm{~V}$ and $3.0 \mathrm{~V}$.

an annealing procedure. The as-prepared hierarchical $\mathrm{CoO}$ nano/microstructures exhibit superior electrochemical performance as anode materials for LIBs. A high discharge capacity of $1370 \mathrm{mAh} / \mathrm{g}$ and the retained discharge capacity of about $1144 \mathrm{mAh} / \mathrm{g}$ over 20 cycles are achieved at a current density of $100 \mathrm{~mA} / \mathrm{g}$. The excellent electrochemical performance might originate from these unique $\mathrm{CoO}$ nano/microstructures. Our works shed light on the extending applications of $\mathrm{CoO}$ as anode materials for high power LIBs.

\section{Conflict of Interests}

The authors declare that there is no conflict of interests regarding the publication of this paper.

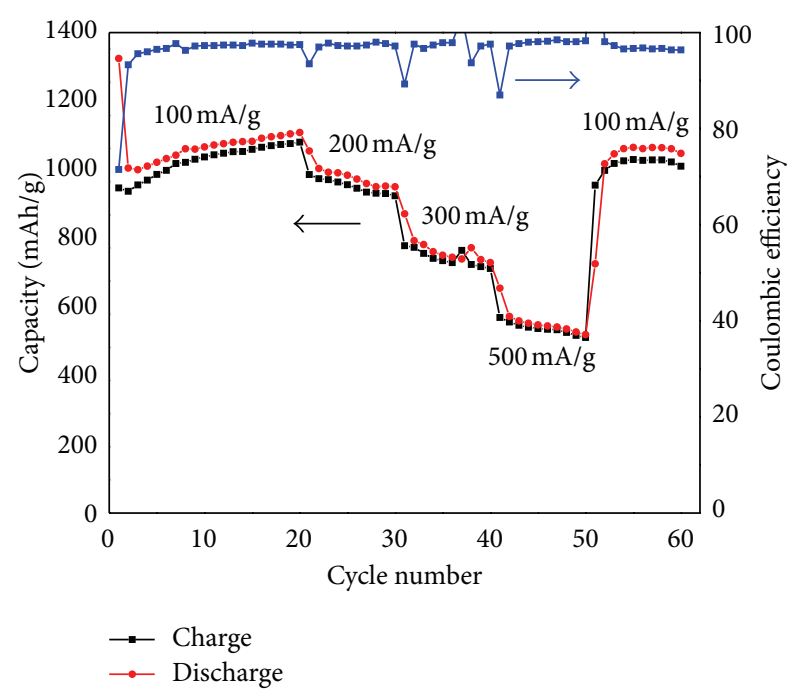

FIGURE 4: The specific capacity and the coulombic efficiency of $\mathrm{CoO}$ electrode under different current densities (100-500 mA/g).

\section{Acknowledgments}

This work was supported by the National Natural Science Foundation of China (no. 11074254 and no. 51171176) and the Visiting Scholar Project for the Young Core Instructor of Higher Institutions in Shandong Province.

\section{References}

[1] A. S. Aricò, P. Bruce, B. Scrosati, J.-M. Tarascon, and W. van Schalkwijk, "Nanostructured materials for advanced energy conversion and storage devices," Nature Materials, vol. 4, no. 5, pp. 366-377, 2005.

[2] K. S. Kang, Y. S. Meng, J. Bréger, C. P. Grey, and G. Ceder, "Electrodes with high power and high capacity for rechargeable lithium batteries," Science, vol. 311, no. 5763, pp. 977-980, 2006.

[3] D. D. Li, L. X. Ding, S. Q. Wang, D. D. Cai, and H. H. Wang, "Ultrathin and highly-ordered $\mathrm{CoO}$ nanosheet arrays for lithium-ion batteries with high cycle stability and rate capability," Journal of Materials Chemistry A, vol. 2, no. 16, pp. 5625-5630, 2014.

[4] P. Poizot, S. Laruelle, S. Grugeon, L. Dupont, and J. M. Tarascon, "Nano-sized transition-metal oxides as negative-electrode materials for lithium-ion batteries," Nature, vol. 407, no. 6803, pp. 496-499, 2000.

[5] F. Li, Q. Q. Zou, and Y. Y. Xia, "CoO-loaded graphitable carbon hollow spheres as anode materials for lithium-ion battery," Journal of Power Sources, vol. 177, no. 2, pp. 546-552, 2008.

[6] X. W. Lou, D. Deng, J. Y. Lee, J. Feng, and L. A. Archer, "Self-supported formation of needlelike $\mathrm{Co}_{3} \mathrm{O}_{4}$ nanotubes and their application as lithium-ion battery electrodes," Advanced Materials, vol. 20, no. 2, pp. 258-262, 2008.

[7] A. Hu, C. Curran, C. Tran, A. Kapllani, and V. Kalra, "Fabrication of transition metal oxide-carbon nanofibers with novel hierarchical architectures," Journal of Nanoscience and Nanotechnology, vol. 14, no. 7, pp. 5501-5507, 2014.

[8] H. Iddir and R. Benedek, "First-principles analysis of phase stability in layered-layered composite cathodes for lithium-ion 
batteries," Chemistry Materials, vol. 26, no. 7, pp. 2407-2413, 2014.

[9] P. Tammawat and N. Meethong, "Synthesis and characterization of stable and binder-free electrodes of $\mathrm{TiO}_{2}$ nanofibers for li-ion batteries," Journal of Nanomaterials, vol. 2013, Article ID 413692, 8 pages, 2013.

[10] Z. P. Wang, G. W. Xie, and L. J. Gao, "Electrochemical characterization of $\mathrm{Li}_{4} \mathrm{Ti}_{5} \mathrm{O}_{12} / \mathrm{C}$ anode material prepared by starch-solassisted rheological phase method for Li-ion battery," Journal of Nanomaterials, vol. 2012, Article ID 876197, 7 pages, 2012.

[11] F. D. Wu and Y. Wang, "Self-assembled echinus-like nanostructures of mesoporous CoO nanorod@CNT for lithium-ion batteries," Journal of Materials Chemistry, vol. 21, no. 18, pp. 6636-6641, 2011.

[12] A. Yu, H. W. Park, A. Davies, D. C. Higgins, Z. Chen, and $\mathrm{X}$. Xiao, "Free-standing layer-by-layer hybrid thin film of graphene- $\mathrm{MnO}_{2}$ nanotube as anode for lithium ion batteries," Journal of Physical Chemistry Letters, vol. 2, no. 15, pp. 18551860, 2011.

[13] C. C. Li, Q. H. Li, L. B. Chen, and T. H. Wang, "Selfassembled echinus-like nanostructures of mesoporous $\mathrm{CoO}$ nanorod@CNT for lithium-ion batteries," Journal of Materials Chemistry, vol. 21, no. 18, pp. 11867-11872, 2011.

[14] W. L. Yao, J. Yang, J. L. Wang, and L. A. Tao, "Synthesis and electrochemical performance of carbon nanofiber-cobalt oxide composites," Electrochimica Acta, vol. 53, no. 24, pp. 7326-7330, 2008.

[15] Y. M. Sun, X. L. Hu, W. Luo, and Y. H. Huang, "Self-assembled mesoporous $\mathrm{CoO}$ nanodisks as a long-life anode material for lithium-ion batteries," Journal of Materials Chemistry, vol. 22, no. 27, pp. 13826-13831, 2012.

[16] X. L. Huang, R. Z. Wang, D. Xu et al., "Homogeneous CoO on graphene for binder-free and ultralong-life lithium ion batteries," Advaced Functional Materials, vol. 23, no. 35, pp. 4345-4353, 2013.

[17] W. Yao, J. Chen, and H. Cheng, "Platelike CoO/carbon nanofiber composite electrode with improved electrochemical performance for lithium ion batteries," Journal of Solid State Electrochemistry, vol. 15, no. 1, pp. 183-188, 2011.

[18] H. Guan, X. Wang, H. Li et al., "CoO octahedral nanocages for high-performance lithium ion batteries," Chemical Communications, vol. 48, no. 40, pp. 4878-4880, 2012.

[19] B. D. Chen, C. X. Peng, and Z. Cui, "Ultrasonic synthesis of $\mathrm{CoO} / g r a p h e n e$ nanohybrids as high performance anode materials for lithium-ion batteries," Transactions of Nonferrous Metals Society of China, vol. 22, no. 10, pp. 2517-2522, 2012.

[20] W. W. Yuan, J. Zhang, D. Xie, Z. Donga, Q. M. Su, and G. H. $\mathrm{Du}$, "Porous $\mathrm{CoO} / \mathrm{C}$ polyhedra as anode material for Li-ion batteries," Electrochimica Acta, vol. 108, pp. 506-511, 2013.

[21] M. Zhang, F. L. Yan, X. Tang, Q. H. Li, T. H. Wang, and G. Z. Cao, "Flexible $\mathrm{CoO}$-graphene-carbon nanofiber mats as binder-free anodes for lithium-ion batteries with superior rate capacity and cyclic stability," Journal of Materials Chemistry A, vol. 2, no. 16, pp. 5890-5897, 2014.

[22] F. Wang, C. C. Lu, Y. F. Qin et al., "Solid state coalescence growth and electrochemical performance of plate-like $\mathrm{Co}_{3} \mathrm{O}_{4}$ mesocrystals as anode materials for lithium-ion batteries," Journal of Power Sources, vol. 235, pp. 67-73, 2013.

[23] J. Cao, H. Liu, J. Xie, G. Cao, and X. Zhao, "Effect of K-doping on the electrochemical performance of $\mathrm{Ca}_{3} \mathrm{Co}_{4} \mathrm{O}_{9}$ anode for $\mathrm{Li}$ ion batteries," Journal of Materials Science \& Technology, vol. 26, no. 7, pp. 669-672, 2010.
[24] M. M. Rahman, J. Z. Wang, X. L. Deng, Y. Li, and H. K. Liu, "Hydrothermal synthesis of nanostructured $\mathrm{Co}_{3} \mathrm{O}_{4}$ materials under pulsed magnetic field and with an aging technique, and their electrochemical performance as anode for lithium-ion battery," Electrochimica Acta, vol. 55, no. 2, pp. 504-510, 2009.

[25] C. H. Chen, B. J. Hwang, J. S. Do et al., "An understanding of anomalous capacity of nano-sized $\mathrm{CoO}$ anode materials for advanced Li-ion battery," Electrochemistry Communications, vol. 12, no. 3, pp. 496-498, 2010.

[26] W. Yao, J. Yang, J. Wang, and Y. Nuli, "Multilayered cobalt oxide platelets for negative electrode material of a lithium-ion battery," Journal of the Electrochemical Society, vol. 155, no. 12, pp. A903-A908, 2008.

[27] S. Wang, J. Zhang, and C. Chen, " $\mathrm{Fe}_{3} \mathrm{O}_{4}$ submicron spheroids as anode materials for lithium-ion batteries with stable and high electrochemical performance," Journal of Power Sources, vol. 195, no. 16, pp. 5379-5381, 2010.

[28] Y. Yu, Y. Shi, and C. H. Chen, "Nanoporous cuprous oxide/lithia composite anode with capacity increasing characteristic and high rate capability," Nanotechnology, vol. 18, no. 5, Article ID 055706, 2007. 

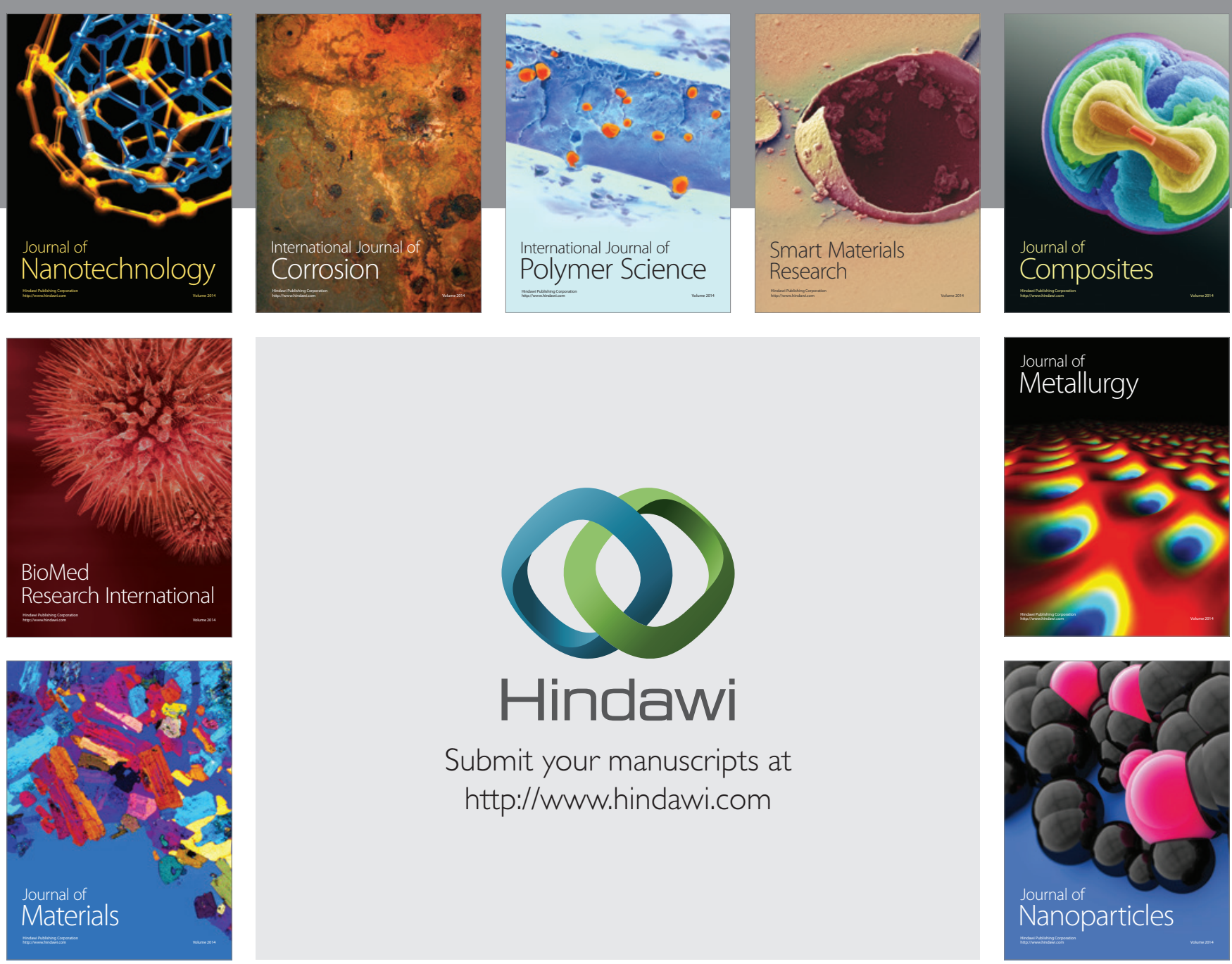

Submit your manuscripts at http://www.hindawi.com
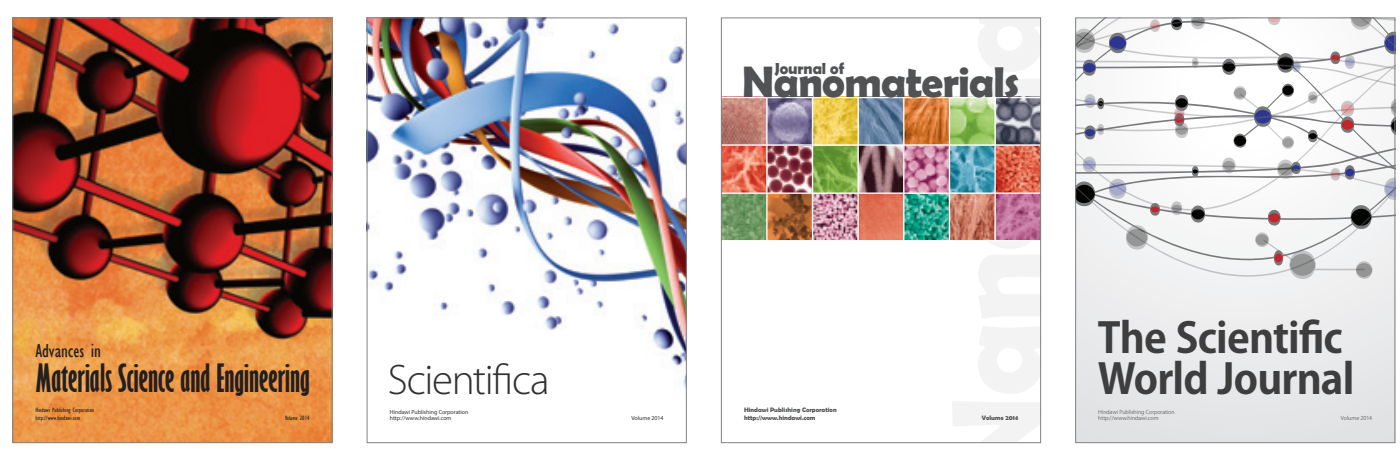

\section{The Scientific World Journal}
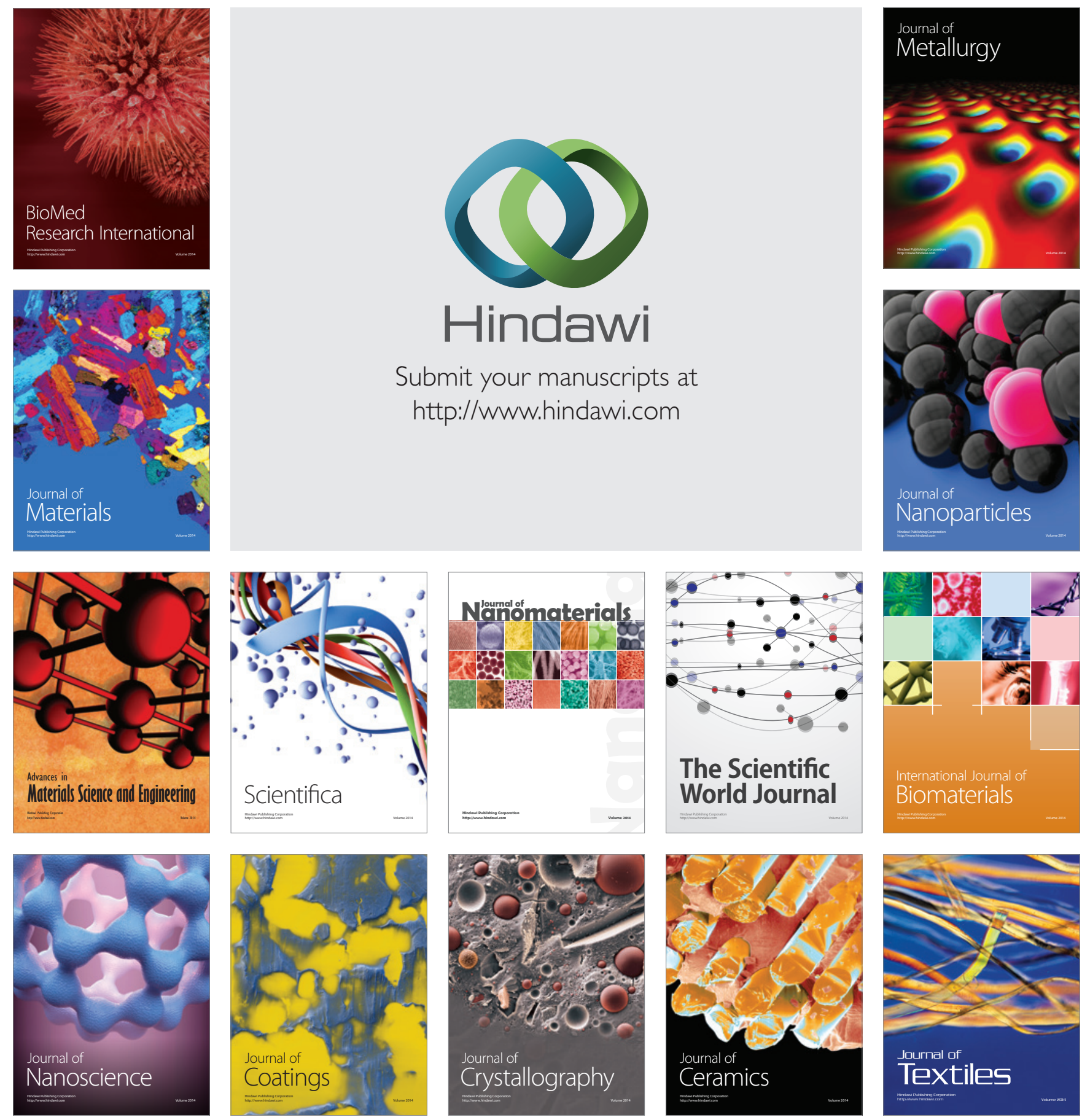